\title{
INFLUÊNCIA DO DESEMPENHO ECONÔMICO FINANCEIRO NAS INOVAÇÕES TECNOLÓGICAS DE EMPRESAS BRASILEIRAS DE CAPITAL ABERTO DA CONSTRUÇÃO CIVIL
}

Data de submissão: 30/01/2014 Aceite: 22/04/2017

Alini da Silva ${ }^{1}$

Ricardo Floriani Nelson Hein ${ }^{3}$

\section{RESUMO}

Com o objetivo de analisar qual a influência do desempenho econômico financeiro nas inovações tecnológicas feitas por empresas brasileiras da construção civil que sustentam suas atividades por meio de capital aberto foi desenvolvido o presente trabalho. Os temas desempenho econômico financeiro e inovações tecnológicas são abordados nos tópicos pertinentes na fundamentação teórica mediante a consulta à diversos autores que, anteriormente, abordaram temas correlatos. O presente estudo configura-se, quanto aos objetivos, como descritivo. Em relação aos procedimentos, enquadra-se como documental e a abordagem refere-se à análise quantitativa. Para a coleta de dados, foram utilizadas as evidências de inovação constantes nos Relatórios de Administração e os resultados econômicos e financeiros (publicados pelas empresas brasileiras de capital aberto do setor de construção civil), obtidos por meio da base Economática ${ }^{\circledR}$. Quanto à técnica estatística, foi utilizada a Regressão Linear Múltipla. Conclui-se que as variáveis de desempenho econômico financeiro, tais como: liquidez geral, tamanho da empresa e crescimento das vendas, apresentaram relação significativa com os índices de inovação tecnológica das empresas de construção civil.

Palavras-chaves: Inovação, Desempenho econômico-financeiro, Construção civil.

\footnotetext{
1 Possui Graduação em Ciências Contábeis pela Universidade Regional Integrada do Alto Uruguai e das Missões URI. Mestre em Ciências Contábeis pela Universidade Regional de Blumenau - FURB. Doutoranda em Ciências Contábeis pela Universidade Regional de Blumenau FURB. Blumenau-SC. Brasil. E-mail: alinicont@gmail.com

2 Possui graduação em Engenharia Civil pela Universidade Regional de Blumenau, FURB, graduação em Administração - Gestão Imobiliária pelo Centro Universitário Leonardo da Vinci, UNIASSELVI, mestrado em Administração pela FURB e doutorado em Ciências Contábeis e Administração pela FURB. Blumenau-SC. Brasil.

E-mail: ricardo.floriani@uniasselvi.com.br

3 Possui graduação em Ciências de I Grau pela Fundação Universidade Regional de Blumenau, FURB, graduação em Matemática pela FURB, mestrado em Engenharia de Produção pela Universidade Federal de Santa Catarina, UFSC e doutorado em Engenharia de Produção pela UFSC. Blumenau -SC. Brasil. E-mail: hein@furb.br
} 


\section{INTRODUÇÃO}

A inovação empresarial vem sendo discutida desde o início do século XX, mais especificamente, sua natureza, características, fontes e classificação, a fim de compreender a sua relação com o desenvolvimento econômico de entidades (MARQUES, 2004). De acordo com Gunday et al. (2011), a inovação é um dos instrumentos fundamentais de estratégias de crescimento, para empresas que pretendem se expandir em novos mercados, por ter vantagem competitiva.

A inovação é um termo utilizado não somente para designar novos produtos e processos, mas também porque se relaciona ao marketing e a organização (GUNDAY et al., 2011). Inovações em novos produtos, processos, custos ou melhorias organizacionais permitem que entidades se diferenciem e se destaquem no mercado de atuação pelo aumento de sua eficiência e diminuição de custos (HASHI, STOJCIC, 2013).

Em um contexto socioeconômico em que a competitividade permeia o dia a dia das organizações, a implementação de diferenciais pode se constituir em condição básica para a permanência do produto, ou até mesmo da empresa no mercado. Além de possibilitar alongamento da curva de vida da empresa, as inovações podem potencializar indicadores econômicos e financeiros das empresas, comparativamente, mais inovadoras (FLORIANI, 2009).

De acordo com Brito, Brito e Morganti (2009), a relação entre a inovação e o desempenho empresarial vem sendo discutida na literatura. Desta forma, verifica-se que o objetivo de estudo é averiguar como o desempenho econômico financeiro influi nas inovações tecnológicas das empresas de capital aberto da área de construção civil.

Estudos nacionais, tais como o de Brito, Brito e Morganti (2009), Santos, Basso e Kimura (2010) e Santos et al. (2014), analisaram a relação entre a inovação e o desempenho de empresas brasileiras. Foram usados nessas analises dados do IBGE; o grau de relacionamento do construto inovação com as variáveis que representam o desempenho das firmas, com informações referentes à inovação de empresas extraídas do PINTEC, dos anos de 2000, 2003 e 2005; e análise do relacionamento potencial entre inovações, com dados do PINTEC, e performance de empresas brasileiras.

Estudos internacionais por sua vez, tais como os de Hall e Bagchi-Sem (2002), Marques (2004), Liao e Rice (2010), Kostopoulos et al. (2011), Gunday et al. (2011). Horta, Camanho e Costa (2012), Wang e Wang (2012), Hashi e Stojcic (2013), Hung e Chou (2013), Klingenberg et al. (2013), Ivanov e Avasilcai (2014), verificaram o impacto da inovação no desempenho econômico-financeiro; na estratégia de mercado; na performance financeira e organizacional, como performances inovadoras, de produção, mercadológicas e financeiras; e na excelência do setor de empresas. Além disso, identificaram os indicadores organizacionais chave que são usados para mensurar o processo de inovação organizacional.

O presente estudo se justifica, devido ao fato que o tema inovação organizacional vem sendo amplamente discutido em ambientes científicos da área de ciências sociais a nível internacional, dado a sua relevância e importância, porém, poucos vêm estudando a nível nacional. Desta forma, esta pesquisa contribuirá no aprofundamento do tema, e se difere dos estudos nacionais já citados, que verificaram inovações empresarias com o desempenho de empresas, enquanto que o presente estudo averigua a influência do desempenho empresarial sobre as inovações tecnológicas em empresas de construção civil.

Relacionar resultados de indicadores econômicos e financeiros com as inovações tecnológicas, pode confirmar a hipótese de que se mantém uma relação direta entre os resultados alcançados pelas empresas e a atividade inovadora. A escolha do setor da construção civil se justifica pelo tamanho e importância deste em considerável fatia do PIB brasileiro, bem como pelo emprego intensivo de mão de obra com baixo grau de instrução formal. 


\section{FUNDAMENTAÇÃO TEÓRICA}

Nesta seção, com o intuito de dar suporte teórico ao presente estudo, apresenta-se o referencial teórico, utilizado no estudo, acerca de inovação com foco em tecnologias, desempenho econômico financeiro e estudos correlatos.

\subsection{Inovações Tecnológicas}

A natureza da competição pode ser, fortemente, influenciada pelas inovações tecnológicas, as quais podem romper mercados, mudar a importância relativa dos recursos, bem como, desafiar capacidades de aprendizagem. Contudo, para as organizações estabelecidas, a inovação pode criar riscos e incertezas. O impacto de uma inovação pode fazer com que as empresas utilizem tecnologias ultrapassadas, comprometendo suas chances de sobrevivência, ou também arriscar-se cedo demais com ela (CLEGG; HARDY; NORD, 1998).

Vantagens competitivas são obtidas por meio de iniciativas inovadoras quando os concorrentes são vagarosos em suas reações e abrange novas tecnologias e formas de fazer as coisas. Pode ser através de um novo desenho do produto, um novo processo de produção, uma abordagem diferenciada de marketing ou novos métodos de treinamento. Grande parte das inovações são triviais e incrementais, oriundas de ideias que já circulavam, mas não haviam sido adotadas com vigor. A inovação necessita pressão, desafio e adversidade. A maioria delas requerem melhorias contínuas para reduzir o potencial de imitações. A liderança deve estar disposta a sacrificar a vida fácil, pois é responsável pela criação de um ambiente dinâmico e desafiador, e a empresa não deve se esquivar de pressões e desafios, até porque a vantagem competitiva resulta da meIhoria contínua e não da proteção dos segredos atuais (PORTER, 1999).

Tidd, Bessant e Pavitt (2008) informam que produtos novos permitem o aumento da lucratividade por meio da ocupação de fatias de mercado e os produtos maduros (estabelecidos) geram aumento nas vendas mediante a oferta de preços mais baixos, de modelos novos e customizados e produto com qualidade, além de serviço rápido e eficiente. As vantagens, geradas pelas medidas inovadoras, têm seu poder competitivo reduzido com a imitação dos concorrentes. São apresentadas, por Tidd, Bessant e Pavitt (2008), as vantagens estratégicas: oferecer o que ninguém mais consegue, ou seja, alguma coisa que os outros não consigam imitar; disponibilizar algo de difícil domínio e que exija o pagamento de licença ou taxa (proteção legal de propriedade intelectual); alterar a base de concorrência, tendo, assim, a vantagem de ser o primeiro a entrar ou de ser o seguidor rápido.

A diferença no comportamento econômico das empresas e das nações é explicada, segundo Drucker (2008), pelo empreendedor. Esse complementa que a alta tecnologia pode não ser capaz de gerar vantagem competitiva e menciona ainda que o aparecimento da economia empreendedora é obtido por meio da inovação sistemática, apresentada como a busca e aproveitamento de oportunidades para proporcionar a satisfação das carências e necessidades humanas. Também, conceitua a inovação como o instrumento dos empreendedores para explorar a mudança como uma oportunidade. Para Drucker (2008, p. 39) "não existe algo chamado de recurso até que o homem encontre um uso para alguma coisa na natureza e assim o dote de valor econômico" e qualquer mudança no potencial gerador de riqueza em recursos existentes se constitui em inovação.

A inovação, considerada por Tadeu e Salum (2012), é uma opção estratégica útil para criação de ambiente propício com o envolvimento dos stakeholders do processo, por meio da cultura e estrutura, com o uso de indicadores para acompanhamento e desenvolvimento da capacidade criativa das empresas. A inovação, para os autores, vai além do desenvolvimento tecnológico e abrange 
produtos, processos, modelos de gestão e de negócios. Por fim, definem essa como fazer algo novo, como um processo de amadurecimento que conduz a aplicação prática, percebida e aceita pelos clientes. Tidd, Bessant e Pavitt (2008) afirmam que a habilidade no estabelecimento de relações, a deteç̧ão e aproveitamento da oportunidade é o que move a inovação.

Para Tadeu e Salum (2012), a mensuração do retorno alcançado com os processos inovadores é tão importante quanto o investimento em inovação, e apresentam os tipos de inovação: inovação de produto (benefício nas características do produto que altera a percepção dos consumidores); de processo: (melhoria do processo produtivo com aumento de produtividade ou redução de custos) e de modelo de negócio (mudança na forma como o produto é oferecido ao mercado). As inovações podem ser incrementais (representados por pequenos avanços nos benefícios percebidos pelos clientes) ou radicais (gera um novo paradigma que modifica o modelo de negócios vigente). A gestão da inovação precisa captar indícios de mudança e estar atenta a novas áreas (TADEU; SALUM, 2012).

Tidd, Bessant e Pavitt (2008) também apresentam os tipos de inovações (4P's): Produto, Processo, Posição (mudança no contexto que produtos e serviços são introduzidos) e Paradigma (modelos mentais subjacentes que orientam o que é feito pela empresa). A inovação pode, da mesma forma, ser decorrente do reposicionamento da percepção de um produto ou processo e, na maioria das vezes, ocorre de forma incremental, de forma que os ganhos cumulativos de eficiência são muito maiores a longo prazo do que aqueles obtidos com mudanças radicais ocasionais.

A relação da inovação com o conhecimento é proposta por Tidd, Bessant e Pavitt (2008). Mencionam que a combinação dos conjuntos de conhecimento, em uma inovação bem-sucedida, ocorre sob condições de alta incerteza, e a gestão da inovação envolve a capacidade de extrair conhecimento das incertezas e mobilizar recursos para reduzir esta incerteza em uma ação de equilíbrio. Eles complementam que a inovação não é fácil, mas é imprescindível. A apropriação dos benefícios da inovação é identificada por nove fatores que influenciam a capacidade da empresa de se beneficiar comercialmente de sua tecnologia. São estes: sigilo, conhecimento tácito acumulado, tempo de produção e serviço pós-venda, curva de aprendizagem, recursos complementares, complexidade do produto, padrões, pioneirismo em produtos radicalmente novos e garantia de proteção de patente.

Ettlie (2006) apresenta as respostas competitivas para novos produtos: a) As organizações geralmente competem baseadas nos pontos fortes e tendem a não mudar caso novas capacidades sejam requeridas; b) Quanto mais significante for um movimento empresarial, mais provável que a resposta significativa seja adiada; c) Novos entrantes tipicamente desafiam com novas tecnologias em seus produtos e serviços, mas geralmente são ignorados pelos concorrentes; d) Quando um produto é anunciado ou introduzido, existe $50 \%$ de chance que os competidores respondam com um novo produto; e) Em indústrias com alta proteção por patentes, as empresas preferirão reagir à introdução de novos produtos com uma resposta de mix de marketing e não com novos produtos; f) Os novos entrantes são considerados importantes a partir do momento que se tornam empresas estabilizadas. Para Ettlie (2006) está claro que novos produtos são partes resultantes dos movimentos competitivos de todas as empresas e quanto maior a percepção da ameaça, maior a resposta. No entanto, as empresas nem sempre veem movimentos, especialmente pelos novos entrantes, como grandes ameaças, ou elas acreditam que a proteção por patentes servirá como amortecedor para proteger dos movimentos competitivos. 


\subsection{Desempenho econômico financeiro}

De acordo com Bortoluzzi et al. (2011), a conscientização dos clientes em exigir bens com qualidade, a concorrência entre as empresas, a importância dos funcionários para a empresa e o impacto das atividades empresarias na sociedade tem gerado a necessidade das organizações aderirem a modelos de gestão, a fim de produzir informações úteis e relevantes sobre seu desempenho, auxiliando na tomada de decisões por parte dos gestores.

As demonstrações contábeis são as principais fontes de dados e informações para a análise de desempenho econômico financeiro de empresas, em que indicadores são formados por meio dos relatos históricos e projeções para o futuro (NETO, 2003). Os indicadores econômicos financeiros, considerados tradicionais, são os de liquidez, de rentabilidade e de estrutura de capital, em que trazem informações importantes e complementares para os gestores organizacionais e para suas tomadas de decisões (BORTOLUZZI et al., 2011).

Fischmann e Zilber (2009) argumentam que os índices financeiros principais, por convenções geradas da administração contábil, são os de liquidez, rentabilidade e endividamento. Os indicadores de desempenho econômico financeiro devem ser considerados como ferramenta aos processos de planejamento estratégico e controle. Trentin (2009) complementa ainda que a análise de desempenho organizacional por meio de indicadores possibilita ações em determinadas situações pela demonstração dos pontos fortes e fracos das empresas.

A medição do desempenho organizacional é importante por representar um panorama da organização frente à concorrência, ao mercado, à globalização, às tecnologias e às tendências gerenciais. O desempenho organizacional pode ser medido por diversos aspectos, como: eficácia, eficiência, qualidade, produtividade, qualidade de vida no trabalho por parte dos colaboradores, inovação e lucratividade (SIQUEIRA; ROSA; OLIVEIRA, 2003).

O papel da medição do desempenho empresarial nas organizações depende da necessidade dessa prática para a organização, utilizada como instrumento de controle, a fim de melhorar a performance organizacional e outras variadas aplicações (LIMA; PONTE, 2006). Os métodos e medidas disponíveis para avaliação de desempenho são utilizados de acordo com as expectativas de informações de gestores, seja financeira, econômica social ou outra (BRAGA; MARQUES, 2000). Teixeira e Amaro (2013) afirmam que a avaliação do desempenho financeiro em organizações é uma das perspectivas mais importantes por sintetizar o impacto de todas as decisões de gestores na capacidade de criação de valor da empresa aos seus usuários.

Kanesiro (2008) diferencia os indicadores de desempenho em dois tipos, os absolutos e os relativos ou índices. As medidas absolutas financeiras ou não financeiras são representadas pelo valor do lucro ou prejuízo do exercício ou volume de vendas, ou seja, são os valores absolutos de determinada informação. Já os indicadores relativos ou índices são o resultado de comparação de médias ou de indicadores absolutos, como ROA, ROI, dentre outros.

O índice econômico financeiro, segundo Matarazzo (2008), é a relação entre contas ou o conjunto delas, que evidenciam aspectos da situação econômica ou financeira de uma empresa, encontradas nas demonstrações contábeis e financeiras. A avaliação do desempenho econômico financeiro torna-se importante às empresas (BORTOLUZZI et al., 2011; NETO, 2003; FISCHMANN e ZILBER, 2009, TRENTIN, 2009; SIQUEIRA, ROSA, OLIVEIRA, 2003;LIMA, PONTE, 2006;BRAGA, MARQUES, 2000;TEIXEIRA e AMARO, 2013; KANESIRO, 2008;MATARAZZO,2008), pois verificam os pontos fortes e fracos das atividades, bem como potenciais operações que se destacam em um conjunto, aumentando a rentabilidade da empresa, ou reportando a índices baixos de competitividade. Desta forma, torna-se necessária a verificação de possíveis causas operacionais que podem influenciar neste desempenho, a fim de geri-lo de forma adequada, assegurando o patrimônio de seus usuários. 


\subsection{Estudos Correlatos}

Nesta seção apresentam-se estudos sobre inovação tecnológica, relacionados com o desempenho econômico financeiro de empresas brasileiras e demais países, os quais são necessários para a confrontação dos resultados da presente pesquisa com os demais estudos.

Hall e Bagchi-Sem (2002) analisaram a relação entre as medidas de inovação e desempenho empresarial de empresas canadenses, sendo que o período de análise compreendeu os anos de 1994 a 1997. Os resultados demonstraram que a inovação de produto apresentou relação com o desempenho do negócio das empresas analisadas.

Marques (2004) averiguou o impacto da inovação no desempenho econômico-financeiro, ao longo do período 1995-2001, de empresas industriais portuguesas para identificar os determinantes do processo de inovação. As variáveis de desempenho econômico financeiro utilizadas foram resultado do retorno operacional (RRO), o retorno sobre o investimento (ROI), o crescimento das vendas e o crescimento dos recursos ou do ativo total. Como resultado, verificou-se que as empresas inovadoras apresentaram um melhor desempenho econômico-financeiro do que as empresas não inovadoras e que o nível de intensidade tecnológica da empresa está diretamente ligado com a inovação da empresa e seu desempenho. Como variáveis determinantes no processo de inovação, verifica-se investimento em maquinaria e equipamento, investimento total em inovação, percentagem de vendas resultante de novos produtos, inovação de processo e intensidade de exportação.

Brito, Brito e Morganti (2009) pesquisaram a relação entre a inovação e o desempenho de empresas brasileiras, usando dados da Pesquisa Industrial - Inovação Tecnológica do IBGE. Os achados do estudo apontaram que as variáveis de inovação não explicaram a variabilidade dos indicadores de lucratividade das empresas, todavia, esclareceram a taxa de crescimento da receita líquida das empresas em análise.

Liao e Rice (2010) desenvolveram e testaram um modelo relativamente parcimonioso que ligava o desempenho das empresas, inovações e engajamento de mercado com um modelo de negócios altamente regular. Para isto, utilizaram as variáveis de inovação: intensidade de P\&D (pesquisa e desenvolvimento), intensidade de treinamento, intensidade de produção tecnológica e as variáveis de desempenho: crescimento nas vendas e crescimento esperado nas vendas. Como resultados, os autores verificaram que a performance das empresas é melhorada pela presença da inovação.

Santos, Basso e Kimura (2010) investigaram construtos referentes a inovação, bem como avaliaram a intensidade do relacionamento entre inovação e desempenho das firmas. As informações referentes à inovação de empresas foram extraídas das bases de dados da PINTEC, dos anos de 2000, 2003 e 2005, e dados relativos ao desempenho empresarial foram levantados junto à SERASA e à Gazeta Mercantil. Os achados do estudo validaram a informação de que a inovação influencia positivamente o desempenho financeiro das organizações, em que as variáveis latentes previstas foram consolidadas numa única variável associada à capacidade de inovar.

Kostopoulos et al. (2011) observaram a influência dos efeitos de diferentes conhecimentos externos na capacidade absortiva e testaram os efeitos diretos e indiretos da capacidade absortiva nas inovações e vantagens financeiras, a partir de variáveis de performance de inovação e performance financeira. Os resultados foram que o valor da capacidade absortiva, como um meio para alcançar inovações superiores e performance financeira, transformam o conhecimento externo em ganhos de performance relacionados.

Gunday et al. (2011) exploraram os efeitos das inovações de processos, produtos e mercado nos diferentes aspectos da performance de empresas, incluindo performances inovadoras, produtivas, mercadológicas e financeiras, baseadas em um estudo empírico com 184 empresas 
na Turquia. Para isso, utilizaram as variáveis para inovação: inovações organizacionais, inovações mercadológicas, inovações de processo, inovações de produto (cada uma com suas respectivas variáveis); e para a mensuração de desempenho utilizaram: lucros / total de ativos, lucratividade geral da empresa, lucro/total de vendas, fluxo de caixa, excluindo investimentos. Ademais, performance inovativa, performance de produção e performance de mercado. Os resultados demonstraram que há efeitos positivos entre inovações e performance das empresas.

Horta, Camanho e Costa (2012) examinaram as tendências do desempenho de empresas construtoras portuguesas e identificaram os fatores que promovem excelência e inovação no setor. 0 estudo revelou que a indústria de construção portuguesa teve a experiência de melhora de desempenho durante os anos 1990, mas este crescimento diminuiu nos últimos anos. Com isto, conclui-se que o desempenho das empresas é fortemente afetada pelo contexto econômico nacional e que as pequenas companhias especializadas e grandes contratantes tendem a alcançar melhores níveis.

Wang e Wang (2012) investigaram o relacionamento quantitativo entre compartilhamento de conhecimento, inovações e performance. Os achados foram de que o compartilhamento de práticas de conhecimento explícito e tácito facilita a inovação e a performance, enquanto o compartilhamento de conhecimento tácito tem efeitos mais significantes na qualidade da inovação e performance operacional.

Hashi e Stojcic (2013), em seu estudo, tiveram como objetivo apresentar uma das primeiras tentativas para comparar os determinantes do processo de inovação em mercados maduros do oeste europeu com a economia de transição que recentemente juntou a União Europeia. Os resultados apresentaram que há relacionamento positivo entre atividades de inovação e produtividade. As empresas maiores são mais propensas a desenvolver atividades de inovação e investem mais em inovações, mas as saídas de inovação decrescem com o tamanho da empresa. Os resultados revelam importantes diferenças no comportamento de empresas nos dois grupos de países.

Hung e Chou (2013), em sua pesquisa, objetivaram explorar os efeitos diretos e interativos em duas dimensões de inovação (aquisição de tecnologia externa e exploração de tecnologia externa) na performance da empresa e examinar os efeitos moderados dos dois fatores (P\&D interno e turbulência ambiental) no relacionamento entre ambos os tipos de inovação aberta e performance organizacional. Os achados apresentaram que a aquisição de tecnologia externa afeta positivamente a performance das empresas. Ambas, aquisição de tecnologia externa e exploração de tecnologia externa, estão positivamente relacionados com a performance da empresa sobre alto investimento em P\&D em ambiente mercadológico turbulento. No entanto, turbulência tecnológica somente afeta positivamente o relacionamento entre aquisição de tecnologia externa e performance da empresa, mas não exploração de tecnologia externa e performance da empresa.

No estudo de Klingenberg et al. (2013), objetivou-se questionar ROA e ROE como métricas adequadas para determinar o impacto de atividades particulares isoladas com JIT implementation na performance econômica. Os resultados demonstraram que os efeitos da regressão não possuem relação consistente entre ROA, ROE, BEP e gerenciamento das taxas de saída de invenções. O impacto de uma estratégia operacional individual é difícil de isolar de outras atividades da empresa, como o gerenciamento financeiro. Então, taxas de lucratividade, como ROA, ROE e $B E P$, que agregam todas as atividades da empresa, não são métricas adequadas para determinar os efeitos dos métodos JIT/Lean Manufacturing na performance financeira da empresa.

Santos et al. (2014) tiveram como propósito a aplicação de análise de fatores exploratórios e modelagem de equações estruturais, sendo que esse estudo propõe construtos que podem ser associados ao fenômeno da inovação. Com dados do PINTEC e informações financeiras do Serasa e Gazeta Mercantil, esse estudo avaliou o relacionamento potencial entre inovações e a performance das empresas brasileiras. Os achados sugeriram a associação das variáveis com 
investimentos em inovação, que estão conectados aos esforços inovativos de uma empresa, e não explicam significativamente a performance financeira. Algumas variáveis observadas podem construir um relevante fator associado a inovação, no entanto, o estudo não evidenciou que o fator latente de inovação influenciou a performance financeira da empresa.

Por fim, o estudo de Ivanov e Avasilcai (2014) pretendeu identificar os indicadores organizacionais chave que são usados para mensurar o processo inovativo. As variáveis de inovação utilizadas foram capitalização de oportunidades de desregulação, otimização de oportunidades de negócios, desenvolvimento de serviços inovadores, uso de alianças e JointVentures e alavancagem através de grupos de P\&D. Como variáveis de desempenho, verificou-se percentual de receita de produtos/serviços não regulamentados; de receita de trading, receita de novos serviços; de consumidores servidos através de alianças com Joint Ventures; de P\&D em reuniões de projetos protocolados e NPV de produtos e serviços e. Os resultados encontrados foram de que o quadro analítico, criado pela exploração dos indicadores organizacionais chave, pode ser usado para mensurar a performance do processo de inovação.

Evidencia-se a preocupação teórica de relacionar o desempenho econômico e financeiro das empresas inovadoras. As análises de Hall e Bagchi-Sem (2002), Marques (2004), Gunday et al. (2011), Horta, Camanho e Costa (2012) e Hashi e Stojcic (2013) compreenderam empresas de países desenvolvidos. Brito, Brito e Morganti (2009), Santos, Basso e Kimura (2010) e Santos et al. (2014) utilizaram dados do PINTEC-IBGE.

Este trabalho contribui com a análise de empresas de um país emergente (Brasil) e evidencia a capacidade de geração de resultados econômicos e financeiros com base em inovações evidenciadas, a partir dos relatórios de administração com a utilização de múltiplas variáveis de entrada (inovações) e de saída (resultados econômicos e financeiros) por meio de correlação canônica.

\section{PROCEDIMENTOS METOLODÓGICOS}

O presente estudo configura-se, quanto aos objetivos, como descritivo, já em relação aos procedimentos, enquadra-se como documental e a abordagem refere-se à análise quantitativa. Para a consecução do objetivo de estudo de analisar a influência do desempenho econômico financeiro nas inovações tecnológicas de empresas brasileiras de capital aberto da construção civil, utilizou-se observação e descrição de dados, classificando e interpretando estes por meio de métodos e técnicas precisas (ANDRADE, 2002; TRIVIÑOS, 1987).

Em relação aos procedimentos do estudo, este estudo é classificado como documental (RAUPP e BEUREN, 2004) e utiliza um único delineamento para a análise, organização e interpretação dos dados que se encontram dispersos. Quanto à abordagem do estudo, enquadra-se como quantitativo pelo emprego de métodos quantitativos tanto para a busca de dados como para a análise destes (RICHARDSON, 1989).

A análise compreendeu o período de três anos (2011 a 2013) para cada uma das 19 empresas do setor de construção civil componentes da amostra, compreendendo, portanto, 57 observações para cada uma das variáveis de inovações e de resultados econômicos e financeiros. Os dados de inovações foram coletados a partir dos relatórios da administração, mediante leitura completa do documento e identificação de trechos que evidenciassem a utilização das variáveis em análise. Os dados econômicos e financeiros foram extraídos da Economática ${ }^{\circledR}$. O setor da construção civil foi selecionado para compor o estudo em razão de ser um setor considerado tradicional, pois em setores comprovadamente inovadores, como, por exemplo, o farmacêutico, os resultados financeiros tendem a ser fortemente influenciados pelas inovações e, por isso, 
parece evidente a influência das inovações e os resultados obtidos a partir destas. Pretende-se, desta forma, verificar como ocorre a relação entre as inovações e o desempenho das empresas em setor tradicional de país em desenvolvimento.

O setor da construção civil é caracterizado, por Rossetto (1998), como intenso em competição e incerto e, em decorrência das adaptações, às mudanças no mercado se fazem necessárias. Em razão disso, a perspectiva gerencial precisa moldar-se às novas circunstâncias para possibilitar a sobrevivência organizacional. $\mathrm{O}$ autor descreve o setor como intenso em peculiaridades, como o número grande de empresas, composto por pessoas sem experiência e em alguns casos sem uso de ferramentas, como o planejamento estratégico, e que sofre constantemente efeitos da política e conjuntura econômica, além de ser sensível a política de financiamentos e de poupança da população.

\subsection{População e amostra}

A população do estudo compreendeu todas as empresas listadas no setor de atuação construção e transporte da BM\&FBOVESPA e a amostra foi composta por 19 empresas do segmento de construção civil listadas na BM\&FBOVESPA que tinham todas as informações necessárias a consecução do estudo. No quadro 1, pode-se observar a amostra do presente estudo.

Quadro 1 - Empresas do segmento de construção civil

\begin{tabular}{|c|c|}
\hline \multicolumn{2}{|c|}{ EMPRESAS DO SEGMENTO DE CONSTRUÇÃO CIVIL } \\
\hline Brookfield Incorporações S.A. & Joao Fortes Engenharia S.A. \\
\hline Construtora Adolpho Lindenberg S.A. & Mrv Engenharia e Participacoes S.A. \\
\hline Cr2 Empreendimentos Imobiliarios S.A. & Pdg Realty S.A. Empreend e Participacoes \\
\hline Cyrela Brazil Realty S.A. Empreend e Part & Rodobens Negocios Imobiliarios S.A. \\
\hline Direcional Engenharia S.A. & Rossi Residencial S.A. \\
\hline Even Construtora e Incorporadora S.A. & Sergen Servicos Gerais de Eng S.A. \\
\hline Ez Tec Empreend. e Participacoes S.A. & Tecnisa S.A. \\
\hline Gafisa S.A. & Trisul S.A. \\
\hline Helbor Empreendimentos S.A. & Viver Incorporadora e Construtora S.A. \\
\hline Jhsf Participacoes S.A. & \\
\hline
\end{tabular}

Fonte: Dados da pesquisa.

\subsection{Coleta e análise dos dados}

A coleta de dados se deu por dados primários e secundários. Os dados primários referemse aos índices de inovação tecnológica de Produto, Processo, Posição e Paradigma, propostos por Tidd, Bessant e Pavitt (2008) como os quatro tipos de inovações tecnológicas em organizações.

Orientou-se pelos dizeres do PINTEC - Pesquisa de Inovação Tecnológica para a formação dos índices de inovação, atribuindo pontos à análise de frequência a cada informação encontrada no relatório de administração das empresas da amostra. As informações de inovação foram observadas no site da BM\&FBOVESPA para posteriormente formar o índice de inovação. O PINTEC é uma base conceitual aceita e consolidada internacionalmente, que auxilia no entendimento de estratégias setoriais, com resultados comparáveis e indicadores tradicionais, de motivação e de impacto, (SICSÚ; MELO, 2004).

Quanto aos dados secundários, referem-se às informações constantes no Relatório de Administração, que possibilitaram a extração de evidências de inovação e das informações econômicas financeiras das empresas em análise, os quais foram coletados por meio da base de dados Economática ${ }^{\circledR}$. O período de análise dos dados compreendeu o ano de 2011, 2012 e 2013. Foram selecionados os últimos anos em que os dados das empresas encontravam-se divulgados 
e disponíveis para consulta na data de realização da pesquisa. O período de três anos foi escoIhido para possibilitar a análise de tendência e também para verificar possíveis efeitos defasados no tempo, em que as inovações produzidas, em um período, podem refletir em resultados em períodos futuros. No Quadro 2, verificam-se as variáveis do estudo.

Quadro 2 - Variáveis do estudo

\begin{tabular}{|c|c|c|c|}
\hline Variável & Nome da Variável & Definição & Autores \\
\hline $\begin{array}{l}\text { Dependente 10 } \\
\text { modelo }\end{array}$ & Produto & $\begin{array}{l}\text { Índice formado pela análise de } \\
\text { frequência. }\end{array}$ & $\begin{array}{l}\text { Tidd, Bessant e Pavitt (2008); } \\
\text { PINTEC (2005). }\end{array}$ \\
\hline $\begin{array}{c}\text { Dependente } 2 \text { o } \\
\text { modelo }\end{array}$ & Processo & $\begin{array}{l}\text { Índice formado pela análise de } \\
\text { frequência. }\end{array}$ & $\begin{array}{l}\text { Tidd, Bessant e Pavitt (2008); } \\
\text { PINTEC (2005). }\end{array}$ \\
\hline $\begin{array}{l}\text { Dependente } 30 \\
\text { modelo }\end{array}$ & Posição & $\begin{array}{l}\text { Índice formado pela análise de } \\
\text { frequência. }\end{array}$ & $\begin{array}{l}\text { Tidd, Bessant e Pavitt (2008); } \\
\text { PINTEC (2005). }\end{array}$ \\
\hline $\begin{array}{l}\text { Dependente 4o } \\
\text { modelo }\end{array}$ & Paradigma & $\begin{array}{l}\text { Índice formado pela análise de } \\
\text { frequência. }\end{array}$ & $\begin{array}{l}\text { Tidd, Bessant e Pavitt (2008); } \\
\text { PINTEC (2005). }\end{array}$ \\
\hline Variável & Nome da Variável & Definição & Autores \\
\hline \multirow{9}{*}{ 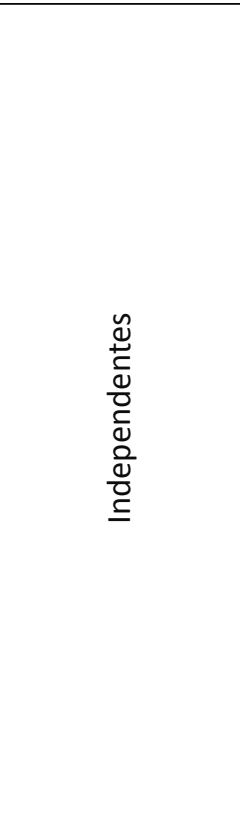 } & ROI & Retorno sobre investimento & $\begin{array}{l}\text { Marques (2004); Gunday et al. } \\
\text { (2011); Horta, Camanho e Costa } \\
\text { (2012); Kanesiro (2008) }\end{array}$ \\
\hline & ROA & Retorno sobre ativo. & $\begin{array}{l}\text { Klingenberg et al. (2013); Santos } \\
\text { et al. (2014); Kanesiro (2008). }\end{array}$ \\
\hline & ROE & Retorno sobre patrimônio líquido. & $\begin{array}{l}\text { Klingenberg et al. (2013); San- } \\
\text { tos et al. (2014); }\end{array}$ \\
\hline & $\begin{array}{l}\text { Crescimento das } \\
\text { vendas }\end{array}$ & $\begin{array}{l}\text { Variação no crescimento das ven- } \\
\text { das. }\end{array}$ & $\begin{array}{l}\text { Marques (2004); Liao e Rice } \\
(2010) ;\end{array}$ \\
\hline & Fluxo de caixa & $\begin{array}{l}\text { Soma do fluxo de caixa operacio- } \\
\text { nal, investimento e financiamento. }\end{array}$ & Gunday et al. (2011); \\
\hline & $\begin{array}{c}\text { Tamanho da em- } \\
\text { presa }\end{array}$ & Total de ativos. & $\begin{array}{l}\text { Horta, Camanho e Costa } \\
\text { (2012); Hung e Chou (2013) }\end{array}$ \\
\hline & Liquidez Geral & $\begin{array}{l}\text { Ativo circulante eativo não circu- } \\
\text { lante, dividido pelo passivo circu- } \\
\text { lante e passivo não circulante. }\end{array}$ & $\begin{array}{l}\text { ludícibus (1998); Matarazzo } \\
\text { (2003); Borba (2006); Silva } \\
\text { (2008). }\end{array}$ \\
\hline & Alavancagem & $\begin{array}{l}\text { Variação percentual no lucro por } \\
\text { ação dividido pela variação per- } \\
\text { centual nas vendas. }\end{array}$ & $\begin{array}{l}\text { Barros e Silveira (2008); Git- } \\
\text { man (2004); Ferreira (2005). }\end{array}$ \\
\hline & Lucro por ação & $\begin{array}{l}\text { Lucro total da empresa, dividido } \\
\text { pela quantidade de ações. }\end{array}$ & $\begin{array}{l}\text { Braga e Marques (2000) e Bor- } \\
\text { toluzzi et al. (2011). }\end{array}$ \\
\hline
\end{tabular}

Fonte: Dados da pesquisa.

Dado o exposto, como método estatístico, aplicou-se Regressão Linear Múltipla aos dados, como forma de dados em painel, com a utilização do softwareSPSS ${ }^{\circledR}$. As variáveis do estudo compreenderam dois grupos de variáveis, os índices de inovação e os de desempenho econômico financeiro, os quais foram distribuídos em quatro modelos para análise, utilizando como variável dependente um dos quatro índices de inovação e como variáveis, independentes aos quatro modelos, as de desempenho econômico financeiro.

O primeiro modelo compreendeu o índice de inovação produto como variável dependente, o segundo modelo compreendeu o índice de inovação processo como variável dependente, o terceiro modelo compreendeu o índice posição como variável dependente e o quarto modelo compreendeu o índice paradigma como variável dependente.

Na próxima seção apresenta-se a consecução dos resultados, com a finalidade de alcançar o objetivo de estudo proposto de examinar a influência do desempenho econômico financeiro nas inovações tecnológicas de empresas brasileiras de capital aberto da construção civil. 


\section{ANÁLISE E DISCUSSÃO DOS RESULTADOS}

Nesta seção, apresenta-se a análise dos resultados, em que primeiramente são abordados os resultados oriundos da aplicação dos testes de aleatoriedade, normalidade e homocedasticidade sobre os dados em análise, com o fim de verificar a normalidade destes. Em seguida, são discutidos os achados oriundos dos quatro modelos de regressão em análise, a fim da consecução do objetivo de pesquisa proposto.

Na Tabela 1, visualizam-se os testes dos pressupostos, aplicados aos dados analisados.

Tabela 1 - Testes de aleatoriedade, normalidade e homocedasticidade

\begin{tabular}{|c|c|c|}
\hline Pressupostos & Testes & Hipóteses \\
\hline \multirow{4}{*}{ 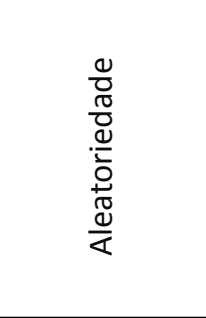 } & $\begin{array}{l}\text { 1o ModeloDurbin-Watson. Estatística } \mathrm{DW}=1,4720 \\
\text { Valor-p }=0,0146 ; \text { Autocorrelação dos resíduos }=0,2640\end{array}$ & \multirow{4}{*}{$\begin{array}{l}\text { Inexiste autocorrelação } \\
\text { de primeira ordem en- } \\
\text { tre os resíduos. }\end{array}$} \\
\hline & $\begin{array}{l}\text { 2 ModeloDurbin-Watson: Estatística DW }=1,7521 \\
\text { Valor-p = 0,1865; Autocorrelação dos resíduos }=0,1240\end{array}$ & \\
\hline & $\begin{array}{l}\text { 30 ModeloDurbin-Watson: Estatística DW }=1,4094 \\
\text { Valor-p = 0,0069; Autocorrelação dos resíduos = 0,2953 }\end{array}$ & \\
\hline & $\begin{array}{l}4 \text { o ModeloDurbin-Watson: Estatística DW }=2,0619 \\
\text { Valor-p = 0,9031; Autocorrelação dos resíduos }=-0,0310\end{array}$ & \\
\hline \multirow{4}{*}{$\begin{array}{l}\frac{0}{0} \\
\frac{\pi}{0} \\
\frac{.0}{0} \\
\frac{1}{0} \\
0 \\
z\end{array}$} & $\begin{array}{l}\text { 10 ModeloShapiro-Wilk: } \\
\text { Estatística SW }=0,8802 ; \text { Valor-p }=0,0001\end{array}$ & \multirow{4}{*}{$\begin{array}{l}\text { A distribuição dos resí- } \\
\text { duos é normal. }\end{array}$} \\
\hline & $\begin{array}{l}\text { 20 ModeloShapiro-Wilk: } \\
\text { Estatística SW }=0,9582 ; \text { Valor-p }=0,0575\end{array}$ & \\
\hline & $\begin{array}{l}\text { 3o ModeloShapiro-Wilk: } \\
\text { Estatística SW = 0,9889; Valor- } p=0,8949\end{array}$ & \\
\hline & $\begin{array}{l}\text { 40 ModeloShapiro-Wilk: } \\
\text { Estatística SW = 0,8476; Valor-p }=0,0000\end{array}$ & \\
\hline \multirow{4}{*}{ 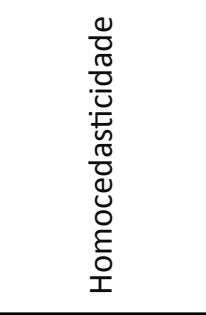 } & $\begin{array}{l}\text { 10 ModeloLevene: } \\
\text { Estatística } \mathrm{F}=0,0409 ; \text { Valor- } \mathrm{p}=0,8406\end{array}$ & \multirow{4}{*}{$\begin{array}{l}\text { A variância dos erros é } \\
\text { uniforme. }\end{array}$} \\
\hline & $\begin{array}{l}\text { 20 ModeloLevene: } \\
\text { Estatística } \mathrm{F}=1,5227 ; \text { Valor- } \mathrm{p}=0,2228\end{array}$ & \\
\hline & $\begin{array}{l}\text { 3o ModeloLevene: } \\
\text { Estatística } \mathrm{F}=0,1721 ; \text { Valor- } \mathrm{p}=0,6800\end{array}$ & \\
\hline & $\begin{array}{l}\quad \text { 40 ModeloLevene: } \\
\text { Estatística } \mathrm{F}=0,5243 ; \text { Valor- } \mathrm{p}=0,4723\end{array}$ & \\
\hline
\end{tabular}

Fonte: Dados da pesquisa.

Com base na Tabela 1, pode-se perceber que o teste de Durbin-Watson, nos quatro modelos analisados, atendeu ao pressuposto da aleatoriedade no procedimento de regressão, demonstrando a inexistência de autocorrelação entre os resíduos. De acordo com Marôco (2003), o valor de Durbin-Watson deve estar próximo de 2.

A normalidade dos dados foi verificada pelo teste Shapiro-Wilk (S-W), o qual compara a "distribuição de frequência acumulada de um conjunto de valores observados da amostra com uma distribuição esperada ou teórica" (FÁVERO et al. 2009, p. 112). Verificou-se, quanto aos modelos analisados, que a distribuição dos resíduos é normal, sem apresentar problemas de normalidade dos dados. E por fim, de acordo com Marôco (2003), o teste de Levene verifica o pressuposto de homocedasticidade dos dados, em que, nos quatro modelos analisados, demonstrou-se com variância dos erros uniforme.

Depois de analisados os pressupostos dos dados, gerou-se quatro regressões lineares múltiplas, com variáveis independentes das de desempenho econômico financeiro, e com variável dependente no primeiro modelo; a inovação de produto; no segundo modelo, a inovação de processo; no terceiro modelo, a inovação de posição e no quarto modelo, a inovação de paradigma, como demonstra os resultados na Tabela 2. 
Tabela 2 - Resultado da regressão linear múltipla

\begin{tabular}{|c|c|c|c|c|}
\hline \multirow{2}{*}{ Variáveis } & \multicolumn{4}{|c|}{ Índices de divulgação do capital intelectual } \\
\hline & Produto & Processo & Posição & Paradigma \\
\hline LiqGer & $\begin{array}{c}-1,962 \\
(0,092)^{* * *} \\
\end{array}$ & $\begin{array}{c}0,283 \\
(0,720) \\
\end{array}$ & $\begin{array}{c}0,590 \\
(0,784) \\
\end{array}$ & $\begin{array}{l}-1,790 \\
(0,560) \\
\end{array}$ \\
\hline Tamanho & $\begin{array}{c}-0,007 \\
(0,989) \\
\end{array}$ & $\begin{array}{c}0,525 \\
(0,133) \\
\end{array}$ & $\begin{array}{c}2,026 \\
(0,036)^{* *}\end{array}$ & $\begin{array}{c}1,638 \\
(0,226) \\
\end{array}$ \\
\hline Fluxo_Caixa & $\begin{array}{c}0,000 \\
(0,404) \\
\end{array}$ & $\begin{array}{c}0,000 \\
(0,147) \\
\end{array}$ & $\begin{array}{c}0,000 \\
(0,492) \\
\end{array}$ & $\begin{array}{c}0,000 \\
(0,541) \\
\end{array}$ \\
\hline ROA & $\begin{array}{c}0,265 \\
(0,397) \\
\end{array}$ & $\begin{array}{c}-0,031 \\
(0,885) \\
\end{array}$ & $\begin{array}{c}0,178 \\
(0,761) \\
\end{array}$ & $\begin{array}{c}0,831 \\
(0,321) \\
\end{array}$ \\
\hline ROE & $\begin{array}{c}-0,052 \\
(0,244) \\
\end{array}$ & $\begin{array}{c}0,016 \\
(0,608) \\
\end{array}$ & $\begin{array}{l}-0,005 \\
(0,954) \\
\end{array}$ & $\begin{array}{l}-0,011 \\
(0,927) \\
\end{array}$ \\
\hline ROI & $\begin{array}{l}-3,266 \\
(0,606) \\
\end{array}$ & $\begin{array}{l}-3,980 \\
(0,363) \\
\end{array}$ & $\begin{array}{r}-18,188 \\
(0,131) \\
\end{array}$ & $\begin{array}{r}-20,040 \\
(0,240) \\
\end{array}$ \\
\hline Alavancagem & $\begin{array}{c}0,010 \\
(0,951) \\
\end{array}$ & $\begin{array}{l}-0,058 \\
(0,600) \\
\end{array}$ & $\begin{array}{c}-0,037 \\
(0,901) \\
\end{array}$ & $\begin{array}{c}-0,197 \\
(0,647) \\
\end{array}$ \\
\hline LPA & $\begin{array}{l}-0,087 \\
(0,731) \\
\end{array}$ & $\begin{array}{c}0,150 \\
(0,391) \\
\end{array}$ & $\begin{array}{c}0,148 \\
(0,755) \\
\end{array}$ & $\begin{array}{c}-0,418 \\
(0,538) \\
\end{array}$ \\
\hline CrescVendas & $\begin{array}{l}-1,702 \\
(0,499) \\
\end{array}$ & $\begin{array}{l}-4,588 \\
(0,011) \\
\end{array}$ & $\begin{array}{c}-9,627 \\
(0,046)^{* *}\end{array}$ & $\begin{array}{r}-11,227 \\
(0,100) \\
\end{array}$ \\
\hline Ano 2013 & - & - & - & - \\
\hline Ano 2012 & $\begin{array}{c}-2,816 \\
(0,199) \\
\end{array}$ & $\begin{array}{c}-3,235 \\
(0,035)^{* *} \\
\end{array}$ & $\begin{array}{c}-19,494 \\
(0,000)^{*} \\
\end{array}$ & $\begin{array}{c}-9,549 \\
(0,106) \\
\end{array}$ \\
\hline Ano 2011 & $\begin{array}{l}-1,279 \\
(0,548) \\
\end{array}$ & $\begin{array}{c}-0,140 \\
(0,924) \\
\end{array}$ & $\begin{array}{c}-9,553 \\
(0,020)^{* *}\end{array}$ & $\begin{array}{l}-6,964 \\
(0,225) \\
\end{array}$ \\
\hline $\mathbf{R}^{2}$ & 0,155 & 0,334 & 0,466 & 0,194 \\
\hline
\end{tabular}

$\left({ }^{*}\right)$ Significativo ao nível de $1 \%,\left(^{* *}\right)$ Significativo ao nível de $5 \%$ e $\left(^{* * *}\right)$ Significativo ao nível de $10 \%$. Valor absoluto da t-estatística entre parênteses.

Fonte: dados da pesquisa.

De acordo com a Tabela 2, as variáveis de desempenho econômico financeiro, tais como: liquidez geral, tamanho da empresa e crescimento das vendas, possuem relação significativa com os índices de inovação tecnológica das empresas de construção civil.

O modelo 1, o qual relaciona o desempenho econômico financeiro com o índice de inovação de produto, apresentou $R^{2}$ de 0,155 e significância ao nível de $10 \%$ entre a variável liquidez geral e inovação de produto. Observou-se uma correlação negativa e estatisticamente significante entre o índice de inovações nos produtos e o índice de liquidez geral das empresas de construção civil. O modelo 2 , por sua vez, demonstrando $R^{2}$ de 0,334 , evidenciou que o desempenho econômico financeiro não teve relação com as inovações de processos, que no ano de 2012, ao nível de significância de $5 \%$, as empresas analisadas diminuíram os investimentos em inovação de processo.

Quanto ao modelo 3, percebeu-se que o tamanho da empresa e o crescimento das vendas apresentaram relação significativa ao nível de $5 \%$ em relação ao índice de inovação posição das empresas. A explicação do modelo 3 apresentou $R^{2}$ de 0,466 . Verificou-se que quanto maior o tamanho da empresa, maior o índice de posição, e quanto maior o crescimento das vendas, menor o índice de inovação/posição das empresas analisadas.

Além disso, verificou-se que, nos anos de 2012 e 2011, houve diminuição deste índice de inovação ao nível de significância de $1 \%$ e 5\%, respectivamente. Em relação ao modelo 4, o qual relaciona o desempenho econômico financeiro com o índice de inovação paradigma, verificou-se que não houve relação significativa entre as variáveis.

Dado o exposto, constatou-se que quanto maior o índice de liquidez geral, menor é o índice de 
inovação de produto. Quanto maior o tamanho da empresa, maior o índice de posição, e quanto maior o crescimento das vendas, menor o índice de posição das empresas analisadas de construção civil.

A maioria dos estudos, correlatos a esta pesquisa, verificaram a influência das inovações sobre o desempenho econômico financeiro das empresas. Dado o objetivo de analisar a influência do desempenho econômico financeiro nas inovações tecnológicas das empresas de construção civil, os achados deste estudo relacionam-se aos resultados de Hashi e Stojcic (2013), ao verificarem que as empresas maiores são mais propensas a desenvolver atividades de inovação e investem mais em inovações. Além do mais, contribui com os estudos de Hall e Bagchi-Sem (2002) e Gunday et al. (2011), ao verificaram relação entre inovações empresariais e performance das organizações.

\section{CONSIDERAÇÕES FINAIS}

A análise da influência do desempenho econômico financeiro nas inovações tecnológicas de empresas brasileiras de capital aberto da construção civil foi realizada no presente trabalho na busca pela consecução do objetivo de pesquisa proposto. Verificados os critérios de aleatoriedade, normalidade e homocedasticidade, percebeu-se respectivamente que inexiste correlação de primeira ordem entre os resíduos, a distribuição entre os resíduos é normal, a variância dos erros é uniforme. Em consonância com Hall e Bagchi-Sem (2002), Marques (2004), Liao e Rice (2010), Santos, Basso e Kimura (2010), cujos resultados demonstraram que a inovação apresentou relação com o desempenho do negócio das empresas analisadas, verificou-se, no presente estudo, que as variáveis de desempenho econômico financeiro, tais como: liquidez geral, tamanho da empresa e crescimento das vendas, possuem relação significativa com os índices de inovação tecnológica das empresas de construção civil.

Constatou-se que quanto maior o índice de liquidez geral, menor foi o índice de inovação de produto. Este fato esclarece e evidencia que empresas que apresentam solidez financeira tem menor necessidade de investir em inovações de produtos, possivelmente porque possuem em seu portfólio produtos já consagrados pelo mercado. Quanto maior o tamanho da empresa, maior o índice de posição, ou seja, melhor o posicionamento de mercado da empresa em relação ao portfólio de inovações e quanto maior o índice de posição das empresas analisadas de construção civil, menor o crescimento das vendas. Neste caso, as empresas já se encontram posicionadas no mercado e o reforço do posicionamento requer muitas ações que não se refletiram em resultados econômicos e financeiros. Desta forma, constata-se que o desempenho das empresas de construção civil, principalmente relacionado à sua liquidez geral, seu tamanho patrimonial e seu crescimento de vendas, interfere na propensão das empresas à inovação de forma direta ou inversa, indicando que as inovações podem gerar resultados econômicos e financeiros positivos ou negativos, ou seja, o maior investimento em inovações pode não se refletir diretamente em lucros em curto prazo.

Empresas com liquidez geral e crescimento das vendas em expansão, conforme analisado, diminuem os investimentos em inovação. Empresas com estrutura patrimonial grande, de acordo com seu ativo total, tendem a investir mais em inovação. Dado o exposto, percebe-se que quando as empresas de construção civil analisadas obtêm valores elevados de liquidez e vendas, os quais são perceptíveis no resultado da empresa, diminuem os gastos com inovação, o que não ocorre quando a empresa possui seu patrimônio em expansão.

Apresentam-se, como limitações do presente estudo, o direcionamento setorial, a quantidade de empresas que compõem o setor da construção civil e o período de análise, limitado a 3 anos, tendo em vista a necessidade de analisar todos os relatórios de administração para obtenção dos dados das variáveis componentes da amostra. 
Como contribuições, destacam-se as evidências de relações entre as inovações e os resultados econômicos e financeiros alcançados pelas empresas de setores considerados tradicionais como é o caso da construção civil.

Para pesquisas futuras, pode-se replicar o estudo das inovações implantadas e os resultados econômicos e financeiros separados por setores, para todas as empresas de capital aberto, que possa contribuir na verificação do comportamento das inovações de distintos segmentos de atuação.

\section{REFERÊNCIAS}

ANDRADE. M. Como preparar trabalhos para cursos de pós graduação: noções práticas. 5 ed. São Paulo: Atlas, 2002.

ASSAF NETO, A. Estrutura e análise de balanços: um enfoque econômico-financeiro. 8. ed. São Paulo: Atlas, 2003.

BARROS, L. A. B. C.; SILVEIRA, A. D. M. Excesso de confiança, otimismo gerencial e os determinantes da estrutura de capital. Revista Brasileira de Finanças, v. 6, n. 3, p. 293-335, 2008.

BORBA, V. R. Do Planejamento ao Controle de Gestão Hospitalar. Qualitymark Editora Ltda, 2006.

BORTOLUZZI, S. C.; ENSSLIN, S. R.; LYRIO, L.; VASCONCELLOS, M.; ENSSLIN, L. Avaliação de desempenho econômico-financeiro: uma proposta de integração de indicadores contábeis tradicionais por meio da metodologia multicritério de apoio à decisão construtivista (MCDA-C). Revista Alcance, v. 18, n. 2, 2011.

BRAGA, R.; MARQUES, J. C. Medidas de avaliação de empresas: uma evidência de suas relevâncias no caso da Companhia Paranaense de Energia-COPEL. Caderno de Pesquisas em Administração, v. 7, n. 4, p. 13-26, 2000.

BRITO, E. P. Z.; BRITO, L. A. L.; MORGANTI, F. Inovação e o desempenho empresarial: lucro ou crescimento? RAE eletrônica, v. 8, n. 1, 2009.

CLEGG, S. R.; HARDY, C.; NORD, W. R. Handbook de estudos organizacionais. CALDAS, M.; FACHIN, R.; FISCHER, T. (coord. Ed. Brasileira); São Paulo: Atlas, 1998.

DRUCKER, P. F. Inovação e Espírito Empreendedor: Práticas e Princípios. São Paulo: Cengage Learning, 2008.

ETTLIE, J. E. Managing Innovation. 2 ed. Oxford: Elsevier, 2006.

FÁVERO, L. P.; BELFIORE, P.; SILVA, F. L.; CHAN, B. L. Análise de Dados: Modelagem Multivariada para tomada de decisões. Rio de Janeiro: Elsevier, 2009.

FERREIRA, J. A. S. Finanças corporativas: conceitos e aplicações. São Paulo: Pearson Prentice Hall, 2005.

FISCHMANN, A. A.; ZILBER, M. A. Utilização de indicadores de desempenho para a tomada de decisões estratégicas: um sistema de controle. Revista de Administração Mackenzie, v. 1, n. 1, p. 9-25, 2009.

FLORIANI, R. Identificação de inovações e seus reflexos nos índices de rentabilidade de empresas brasileiras de capital aberto. Dissertação de mestrado Programa de Pós-Graduação 
em Administração - PPGAD do Centro de Ciências Sociais Aplicadas da Universidade Regional de Blumenau, Santa Catarina, Brasil, 2009.

GITMAN, L. J. Princípios de administração financeira. 10. ed. São Paulo: Pearson Education do Brasil: Addison Wesley, 2004.

GUNDAY, G.; ULUSOY, G.; KILIC, K; ALPKAN, L. Effects of innovation types on firm performance. International Journal Production Economics, n. 133, p.662-676, 2011.

HALL, L. A.; BAGCHI-SEN, S. A study of R\&D, innovation, and business performance in the Canadian biotechnology industry. Technovation, v. 22, n. 4, p. 231-244, 2002.

HASHI, I.; STOJCIC N. The impact of innovation activities on firm performance using a multi-stage model: Evidence from the Community Innovation Survey 4. Research Policy, v. 42, p. 353-366, 2013.

HORTA, I. M.; CAMANHO, A. S.; COSTA, J.M. Performance assessment of construction companies: A study of factors promoting financial soundness and innovation in the industry. International Journal Production Economics, n. 137, p. 84-93, 2012.

HUNG, K; CHOU, C. The impact of open innovation on firm performance: The moderating effects of internal P\&D and environmental turbulence. Tecnovation, n. 33, p. 368-380, 2013.

IUDÍCIBUS, S. Contabilidade Gerencial. São Paulo: Atlas, 1998.

IVANOV, C.; AVASILCAI, S. Measuring the performance of innovation processes: A Balanced Scorecard perspective. Procedia Social e Behavioral Sciences, n.109 p. 1190-1193, 2014.

KANESIRO, J. C. Desempenho econômico-financeiro e análise envoltória de dados (DEA): um estudo em meios de hospedagem no Brasil. 2008. 155 f. Dissertação Mestrado em Turismo e Hotelaria, Universidade do Vale do Itajaí, Santa Catarina, 2008.

KLINGENBERG, B.; TIMBERLAKE, R.; GEURTS, T. G.; BROWN, R. J. The relationship of operacional innovation and financial performance - A critical perspective. International Journal Production Economics, n. 142, p. 317-323, 2013.

KOSTOPOULOS, K.; PAPALEXANDRIS, A.; PAPACHRONI, M.; IOANNOU, G. Absorptive capacity, innovation, and financial performance. Journal of Business Research, n. 64, p.1335-1343, 2011.

LIAO, T.; RICE, J. Innovation investments, market engagement and financial performance: A study among Australian manufacturing SMEs. Research Policy, n. 39 p. 117-125, 2010.

LIMA, A. C. C.; PONTE, V. M. R. Um estudo sobre os fatores-chave na implantação de modelos de medição do desempenho organizacional. BASE-Revista de Administração e Contabilidade da Unisinos, v. 3, n. 3, p. 285-296, 2006.

MARÔCO, J. Análise Estatística com utilização do SPSS. 2ae ed. Lisboa: Sílabo, 2003.

MARQUES, C. S. E. O impacto da inovação no desempenho econômico-financeiro das empresas industriais portuguesas. Tese de doutorado em Gestão, Universidade de Trás-os-Montes e Alto Douro, Portugal, 2004.

MATARAZZO, D. C. Análise financeira de balanços. 6. ed. São Paulo: Atlas, 2003.

MATARAZZO, D. C. Análise financeira de balanços: abordagem básica e gerencial. 6. ed. São Paulo: Atlas, 2008. 
PINTEC. Pesquisa de inovação tecnológica. Instituto Brasileiro de Geografia e Estatística, 2005.

PORTER, M. E. Competição = On competition: estratégias competitivas essenciais. Rio de Janeiro: Campus, 1999.

RAUPP, F. M.; BEUREN, I. M. Caracterização da pesquisa em Contabilidade. In. BEUREN, Ilse Maria (Org.). Como elaborar trabalhos monográficos em contabilidade: teoria e prática. 2 ed. São Paulo: Atlas, 2004.

RICHARDSON, R. J. Pesquisa social: métodos e técnicas. 2 ed. São Paulo: Atlas, 1989.

ROSSETO, C.R. Adaptação estratégica organizacional: um estudo multi-caso na indústria da construção civil - Setor de Edificações. Tese de Doutorado do Programa de Pós-Graduação em Engenharia de Produção da Universidade Federal de Santa Catarina, Brasil, 1998.SANTOS, D. F. L.; BASSO, L. F. C.; KIMURA, H.; KAYO, E. K. innovation efforts and performances of Brazilian firms. Journal of Business Research, n. 67, p. 527-535, 2014.

SANTOS, D. F. L.; BASSO, L. F. C; KIMURA, H. A influência da inovação no desempenho financeiro de empresas brasileiras. Anais: Simpósio de Administração da Produção, Logística e Operações Internacionais, São Paulo: SIMPOI, 2010.

SICSÚ, A. B.; MELO, L. C. P. Estatísticas e Indicadores de Inovação Estatísticas e Indicadores de Inovação no Setor Industrial - PINTEC e o desvendar das estratégias empresariais. Disponível em: http://www.science.oas.org/ricyt/interior/normalizacion/VItaller/S6_\%20Innov/meloppt. pdf. Acesso em: 28 de março de 2014.

SILVA, J. P. Análise financeira das empresas. 9. ed. São Paulo: Atlas, 2008.

SIQUEIRA, M.; ROSA, E. B.; OLIVEIRA, A. F. Medindo o desempenho das pequenas indústrias de malhas: um estudo de caso. Revista Economia \& Gestão, v. 3, n. 6, 2003.

TADEU, H. F. B.; SALUM, F. A. Estratégia, operações e inovação: Paradoxo do crescimento. São Paulo: Cengage Learning, 2012.

TEIXEIRA, N. M. D.; AMARO, A. G. C. Avaliação do desempenho financeiro e da criação de valorum estudo de caso. Revista Universo Contábil, v. 9, n. 4, p. 157-178, 2013.

TIDD, J.; BESSANT, J.; PAVITT, K. Gestão da Inovação. 3d. Porto Alegre: Ed. Bookman, 2008.

TRENTIN, G. N. S. Os elementos da cultura que fazem parte do ambiente inovador e os indicadores de desempenho econômico-financeiros. Dissertação de Mestrado Programa de PósGraduação em Administração do Centro de Ciências Sociais Aplicadas, Universidade Regional de Blumenau, Santa Catarina, Brasil, 2009.

TRIVIÑOS, A. Introdução à pesquisa em ciências sociais: a pesquisa qualitativa em educação. São Paulo: Atlas, 1987.

WANG, Z.; WANG N. Knowledge sharing, innovation and firm performance. Expert Systems with Applications, n. 39 p. 8899-8908, 2012. 